DOI: $\underline{\text { https://doi.org/10.24867/13BE34Filipovic }}$

\title{
SISTEM ZA UPRAVLJANJE DISTRIBUIRANIM IZVORIMA ENERGIJE OD STRANE KRAJNJIH POTROŠAČA
}

\section{SYSTEM FOR MANAGING DISTRIBUTED ENERGY RESOURCES BY END CONSUMERS}

\author{
Filip Filipović, Fakultet tehničkih nauka, Novi Sad
}

\begin{abstract}
Oblast - ELEKTROTEHNIKA I RAČUNARSTVO
Kratak sadržaj - Sa razvojom tehnologije dolazi do nastanka distribuiranih izvora energije (DER) što dovodi do potrebe za nastankom aplikacija za upravljanje $i$ nadzor koje se nazivaju distribuirani sistemi za upravljanje resursima (DERMS). Sa padom cene distribuiranih izvora energije u koje spadaju solarni paneli $i$ baterije dolazi do nastanka prosumer-a. Prosumer predstavlja potrošača koji poseduje DER, što znači da je to potrošač koji u isto vreme $i$ proizvodi $i$ troši električnu energiju. Ovaj rad je baziran na aplikaciji za upravljnje solarnih panela $i$ baterija od strane prosumer-a. Korisnik aplikacije nakon prijavljivanja na servis ima pristup informacijama o trenutnom radu solarnih panela $i$ baterija kao i o trenutnoj potrošnji. Korisnik takođe može da ima pristup istorijskim podacima rada kao $i$ da izvršava manuelno komandovanje solarnih panela ili da pokrene postupak optimizacije sa ciljem ostvarenja što boljih rezultata rada solarnih panela i baterije.
\end{abstract}

Ključne reči: Distribuirani sistem za upravljanje resursima, distribuirani izvori energije, Prosumer- $i$

Abstract - With the development of technology comes the emergence of distributed energy sources (DER) which leads to the need for the emergence of management and monitoring applications called distributed resource management systems (DERMS). With the fall in the price of distributed energy sources, which include solar panels and batteries, prosumers are emerging. Prosumer represents a consumer who owns DER, which means that it is a consumer who at the same time produces and consumes electricity. This paper is based on an application for control of solar panels and batteries by prosumer. After logging in to the service, the user of the application has access to information on the current operation of solar panels and batteries as well as on current consumption. The user can also have access to historical data as well as perform manual commands of solar panels or start the optimization process in order to achieve the best possible operation of solar panels and batteries.

Keywords: Distributed energy management systems, Distributed energy resources, Prosumers

\section{NAPOMENA:}

Ovaj rad proistekao je iz master rada čiji mentor je bio dr Aleksandar Bošković, docent.

\section{UVOD}

Elektroenergetski sistem (EES) predstavlja najveći i najkompleksniji infrastrukturni sistem na svetu. Sastoji se od velikog broja komponenti i učesnika što čini održavanje i upravljanje veoma kompleksnim.

DER predstavlja distribuirane generatore električne energije, od kojih su najčešći solarni paneli, vetrogeneratori i baterije. Iako su DER-ovi obnovljivi izvori energije i dalje mogu da imaju negativan uticaj na životnu sredinu.

Tako da na primer vetrogeneratori prilikom rada proizvode veliku buku koja ometa kretanje ptica, ili solarni paneli koji zauzimaju velike površine. Takođe je potrebno da se obezbedi adekvatan način za odlaganje pokvarenih baterija koje mogu da imaju negativan uticaj na životnu sredinu. Sa druge strane distribucijom DERova može da se reguliše pritisak na životnu sredinu.

Postoje razne tehnologije, polise i korisnički doprinosi koji značajno utiču na razvoj i implementaciju DER-ova unutar EES. To vodi ka pozitivnom ekonomskom i ekološkom razvoju.

Prednosti upotrebe DER-ova:

- Smanjenje operativnih troškova,

- Pobojšanje pouzdanosti,

- Smanjenje ugljenika,

- Dodatni izvori prihoda,

- Omogućava elektrifikaciju vozila.

U nastavku ovog rada, u poglavlju 2, sledi objašnjenje implementacije i korišćenja distriburanog sistema za upravljanje resursima (DERMS). U poglavlju 4 biće opisana funkcionalnost aplikacije na kojoj se ovaj rad bazira. Dok u poglavlju 3 biće opisane tehnologije koje su korišćene prilikom implementacije. Zaključak istraživanja ovog rada dat je u poglavlju 6.

\section{DISTRIBUIRANI SISTEM ZA UPRAVLJANJE RESURSIMA (DERMS)}

Kompanije i mrežni operateri se suočavaju sa izazovima upravljanja različitih DER-ova, i time dolazi do potrebe za razvojom novih tehnologija i poslovnih modela.

Tehnologije koje su dizajnirane za upravljanje sve raznovrsnijim potencijalom DER uređaja, koji su integrisani u distributivnoj mreži, kreću se od hardverskih uređaja pa do softvera koji dobijaju informacije od sofisticiranih alata za analizu podataka. Kako se primena DER-ova povećava tokom vremena, fokus tehnologija za upravljanje se okreće više prema softveru. 
Elektroprivreda i drugi pružaoci energetskih usluga koriste DERMS kako bi upravljali različitom DER-ovima u jednom sistemu.

Postoji dosta različitih tehnologija koja su dobila ime distributed energy management systems (DERMS). Iz tog razloga mogu da se pojave tehnologije pod imenom
DERMS koje zapravo ne predstavljaju konkurenciju jedna drugoj.

Slika 1 pokazuje kako različiti sistemi različitih proizvođača konvergiraju u DERMS. DERMS možda ima sve funkcionalnosti kao i ostali sistemi, ali proizvođači imaju drugačiji pristup datim funkcionalnostima.

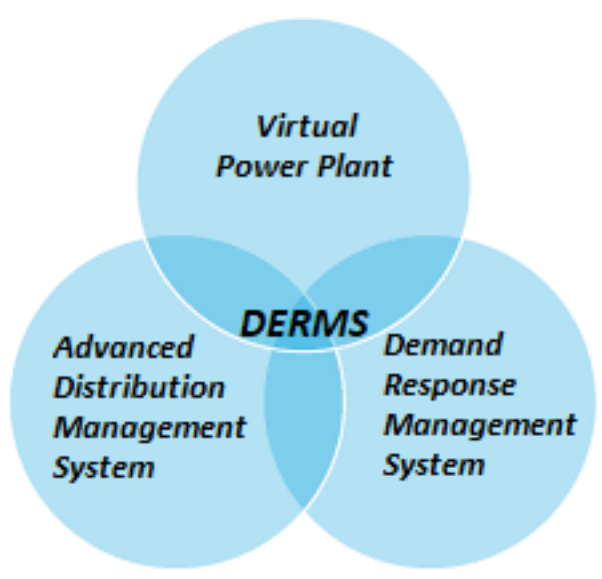

Slika 1. Konvergencija ka DERMS sa drugačijim pristupom

DERMS bi trebalo da nudi programsko rešenje koje je okrenuto korisnicima. Korisnici bi trebali da se uloguju na portal koji im pruža uvid u rad njihovih DER-ova, uvid u potrošnju električne energije kao i informacije o naplati tarifama. Korisnicima se takođe pruža mogućnost potpisivanja ugovora sa mrežnim provajderom, kako bi mogao da vrši prodaju električne energije. Tako da DERMS treba da ima mogućnost prikazivanja informacija o predatoj električnoj energiji u mrežu kao i informacije o zaradi za prodatu električnu energiju.

\section{TECHNOLOGY STACK}

Softversko rešenje na kojem je ovaj rad baziran je implementirano upotrebom $\mathrm{C} \#$ programskog jezika $\mathrm{u}$ Visual Studio 2019 okruženju. Softversko rešenje je veb aplikacija pisana u ASP.NET Core framework-u koji je naslednik od ASP.NET framework-a.

\subsection{ASP.NET Core}

ASP.NET Core je web framework i naslednik ASP.NETa. Razvijen je od strane Microsoft-a. Do verzije 3 je podržavao .NET Framework ali sada podržava samo .NET Core. Framework spaja do sada razdvojene ASP.NET MVC i ASP.NET Web API aplikacije u jedan programski model. I ako je novi framework ima dosta kompatibilnosti sa ASP.NET. ASP.NET Core podržavaju mogućnost da različite aplikacije, pokrenute na istoj mašini, mogu da gađaju različite verzije ASP.NET Core, što nije bilo moguće kod ASP.NET.

Karakteristike ASP.NET Core:

- Vrši automatsko kompajliranje,

- Ima podršku za NuGet pakete,

- Cloud-optimized runtime,

- Generalizovan je putem Open Web Interface for NET,

- Ujedinjuje veb UI i veb API,

- Okruženje spremno za implementaciju na Cloud,

- Light-weight i modular HTTP request pipeline,
- Pruža mogućnost pokretanja aplikacija na različitim platformama (Windows, MacOS i Linux),

- Open-source,

- Ugrađena podrška za dependency Injection.

\section{3 .NET Core vs .NET Framework}

.NET Framework je prvi softverski framework predstavljen od strane Microsoft-a, i mogao je da se koristi samo na Windows operativnom sistemu. .NET Framework pomaže pri razvoju i pokretanju aplikacija. Jedna od mana .NET Framework je u tome što ne podržava doprinose programerske zajednice.

.NET Core nova verzija framework-a koja otkloni ograničenja .NET Framework-a. .NET Core može da se koristi ne samo na Windows operativnom sistemu nego i na Linux i MacOS. Takođe podržava doprinose programerske zajednice.

Dobra strana oba framework-a je u tome što mogu da dele kod i komponente kada je to potrebno. .NET Standard je biblioteka koja se koristi kada je potrebno napisati kod koji je potreban i .NET Core-u i .NET Framework-u.

Tkođe treba dodati da je .NET Core nastao iz potpune rekonstrukcije .NET Framework-a koji je imao dosta "legacy" koda, koji ga je usporavao u razvoju.

\subsection{Veb aplikacija}

Veb aplikacija je softver koji se pokreće na veb servisu, za razliku od kompjuterskih programa koji se pokreću na operativnom sistemu. Veb aplikacijama može da se pristupi preko veb pretraživača od srane svakog korisnika koji ima internet konekciju. Primeri nekih veb aplikacija su Gmail, Yahoo!, Facebook, Erste Bank Net Banking.

ASP.NET Core predstavlja tehnologiju koja se razvila kako bi moglo da se vrši kordinisanje između tehnologija klijentske strane i serverske strane. 


\section{FUNKCIONALNOST APLIKACIJE}

Aplikacija koja se opisuje u ovom dokumentu je namenjena za upravljanje distribuiranim izvorima energije od strane prosumer-a. Distribuirani izvori energije koji se mogu pojaviti u aplikaciji su solarni paneli i baterije.

Aplikacija je realizovana kao veb aplikacija, koja se sastoji iz veb API glavnog servera i veb API simulatora kao i veb UI-ja (korisnički interfejs) preko kojeg korisnici mogu da vrše interakciju sa aplikacijom.

Aplikacija je implementirana kao ASP.NET Core Web Application, za implementaciju glavnog servera i simulatora je korišćen ASP.NET Core Web API šablon dok je za implementaciju korisničkog interfejsa korišćen ASP.NET Core Web App (Model-View-Controller) šablon.

Preko aplikacije korisnici mogu da vide informacije o trenutnoj proizvodnji, potrošnji, količini struje u baterijama i energiji koja se predaje ili uzima iz mreže. Ima prozor u kojem mogu da se prikazuju istorijske informacije rada. Informacije mogu da budu na dnevnom, mesečnom ili godišnjem nivou.

Korisnik takođe ima prikaz o ukupnoj proizvedenoj, potrošenoj i predatoj energiji u mrežu u toku tekućeg meseca.

Korisnik može da kontroliše manuelno rad solarnih panela, gde može da podešava limit proizvodnje solarnog panela, kao i da ga u potpunosti isključi. Takođe može da pozove komandu za automatsku optimizaciju gde će se optimizovati rad solarnih panela i baterije sa ciljem smanjenja potrebe uzimanja električne energije iz mreže.

Takođe postoji ekran sa kog korisnik može da vidi druge korisnike koji pripadaju istoj Area of responsibility i sa kog može da vidi trenutnu proizvodnju, potrošnju, energiju u baterijama i količinu predate ili uzete energije iz mreže.

\section{REZULTATI}

U ovom poglavlju će se predstaviti rezultati rada aplikacije prilikom automatske optimizacije.

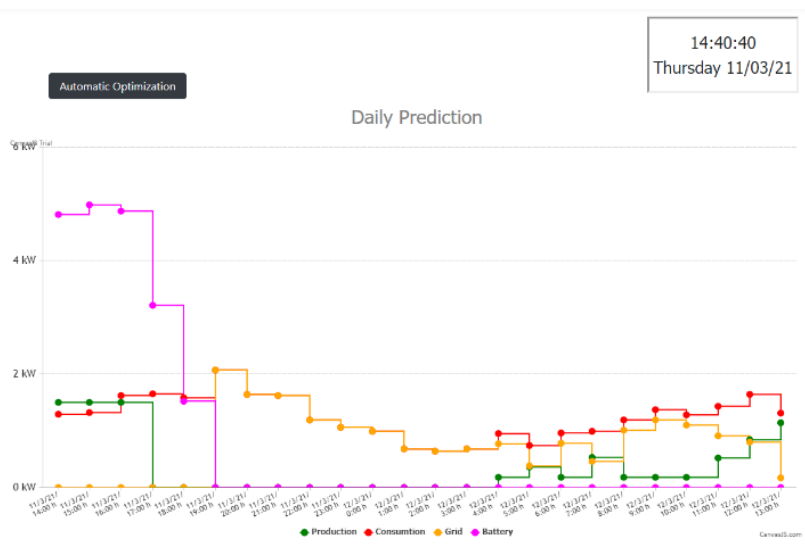

Slika 2. Predikcija rada pre pokretanja automatske optimizacije

Na slici 2 možemo da vidimo kakvo je stanje predikcije rada pre nego što se pokrene automatska optimizacija. Sa slike vidimo da u periodu od 17 časova do 4 časa narednog dana nemamo proizvodnje jer je $u$ tom periodu sunce zašlo i solarni paneli ne mogu da prizvode električnu energiju. Sa slike 2 takođe možemo da vidimo da baterija nije u potpunosti napunjena i da u 19 časova dolazi do potrebe za uzimanjem električne energije iz mreže.

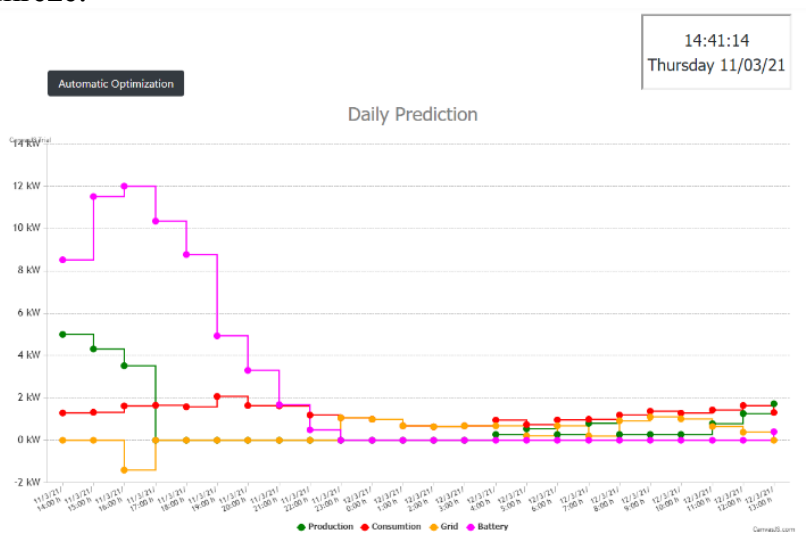

\section{Slika 3. Predikcija rada nakon automatske optimizacije}

$\mathrm{Na}$ slici 3 možemo da vidimo predikciju rada nakon optimizacije. Kao i na slici 2 nema proizvodnje u periodu od 17 časova do 4 časa narednog dana zbog zalaska sunca, ali sada vidimo da je baterija u potpunosti napunjena. Za razliku od slike 2 sada možemo da vidimo da je potrošnja bila zadovoljena iz baterije sve do 23 časa.

Razlog promene predikcije je u promeni ograničenja koje je postavljeno na solarne panele kao maksimalna količina energije koja sme da se proizvede u satu. Takođe, $u$ slučaju da je potrebno, dolazi do pomeranja ograničenja energije koja sme da se unese u bateriju u toku sata.

Iz ovog testa možemo da vidimo kako automatska optimizacija teži tome da smanji potrebu korisnika da uzima električnu energiju iz mreže i pobojša iskorišćenost DER-ova koje korisnik poseduje.

\section{ZAKLJUČAK}

Sa razvojom društva i podizanjem životnog standarda dolazi do sve veće potražnje za električnom energijom. Kako proizvodnja električne energije predstavlja postupak koji značajno utiče na životnu sredinu, dolazi do potrebe za otkrivanjem novih tehnika i tehnologija za generisanje električne energije sa ciljem smanjenja negativnih uticaja po životnu sredinu.

Proizvodnja električne enrgije se sve više okreće upotrebi obnovljivih izvora energije. I ako predstavljaju pobojšanje upotreba obnovljivih izvora energije i dalje može da ima negativnih posledica po životnu sredinu. Rad vetrogeneratora stvara buku koja može da utiče negativno na faunu, takođe zbog svoje veličine mogu negativno da utiču na migraciju ptica. Upotreba solarnih panela stvara potrebu za velikim područjem gde bi se solarni paneli mogli postaviti, što može da dovede do potrebe za sečom šuma. Takođe mora da se nađe adekvatan način za odlaganje starih baterija koje mogu biti jako štetne za životnu sredinu ukoliko se sa njima ne postupa na pravilan način.

Solarni paneli, vetrogeneratori, baterije predstavljaju distribuirane izvore energije koji mogu da se instaliraju blizu samih potrošača. Sa razvojom tehnologije dolazi do pada u ceni što stvara novčano isplativu investiciju gde firme, preduzeća i krajnji potrošači kupuju svoje distribuirane izvore energije, i sa čijom upotrebom mogu da smanje svoje mesečne troškove električne energije. 
Sa distribucijom proizvodnje dolazi do smanjenja pritiska na životnu sredinu. Takođe dolazi do potrebe za nastankom sistema koji će da rukuje i upravlja tim distribuiranim izvorima energije kako bi se očuvao balans u sistemu. I iz tog razloga nastaje aplikacija distribuirani sistemi za upravljanje resursima (DERMS).

Ukoliko krajnji potrošač sklopi ugovor sa elektrodistribucijom pruža mu se mogućnost prodaje viška električne energije.

Cilj rada je bio razvijanje aplikacije za upravljanje solarnih panela i baterija od strane krajnjeg potrošača (prosumer). Krajnjim potrošačima koji poseduju DER-ove je potrebna aplikacija na kojoj mogu da imaju uvid u rad svojih DER-ova. Takođe ukoliko njihovi DER-ovi nisu priključeni na neki distribuirani sistem za upravljanje resursima koji vrši kontrolu rada na globalnom nivou, putem ove aplikacije treba da im se obezbedi funkcija pomoću koje mogu da upravljaju svojim solarnim panelima i baterijama.

Korisnik aplikacije ima mogućnost mauelnog upravljanja solarnim panelima time što može da podešava maksilanu proizvodnju solarnog panela. Takođe može da pozove funkciju za automatsku optimizaciju rada solarnih panela i baterija. Cilj optimizacije je da se obezbedi što efikasniji rad DER-ova sa ciljem što manjeg uzimanja električne energije iz mreže. Sa ovom optimizacijom se postiže i jedan od glavnih ciljeva instalacije distribuiranih izvora energije a to je smanjivanje troškova naplate električne energije na kraju meseca.

Jedan od narednih koraka u razvoju ove aplikacije bi mogla da bude podrška za druge vrse distribuiranih izvora energije, kao što su vetrogeneratori. Dodavanje različitih režima optimizacije kao što je režim za očuvanje životnog veka DER-ova ili režim punjenja baterije u trenucima kada je cena električne energije na tržištu niska takođe mogu da predstave razvojni put kojim ova aplikacija može da pođe.

\section{LITERATURA}

[1] John Twidell, Tony Weir: Renewable Energy Resources, Third Edition, 2015.

[2] D. Yogi Goswami, Frank Kreith: Energy Efficiency and Renewable Energy Handbook, Second Edition, 2016.

[3] Roberto Rodriguez Labastida, Peter Asmus, Brett Feldman: Navigant Research, Distributed Energy Resources Management Systems, 2018.

[4] docs.microsoft.com: Visual Studio 2019 Release Notes, 2021.

[5] Flanagan David: JavaScript - The definitive guide (7 ed.), 2020.

\section{Kratka biografija:}

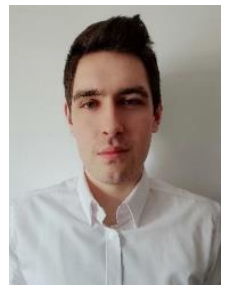

Filip Filipović rođen je 1996. godine u Novom Sadu. Nakon završetka srednje škole 2015. godine, Fakultet tehničkih nauka upisuje iste godine, smer Primenjeno softversko inženjerstvo. Osnovne akademske studije je završio 2019. godine. Master akademske studije upisuje 2019. godine, smer Primenjeno softversko inženjerstvo. 